\title{
Four effects of elevated temperature on chiasma formation in the locust Schistocerca gregaria
}

\section{S. A. Henderson}

Department of Genetics, University of Cambridge, Downing Street, Cambridge CB2 3EH, U.K.

Using an inbred stock of Schistocerca gregaria in which inter-individual variation was reduced, the effects of high temperature treatments on male meiosis have been investigated. These experiments involved both heat-treatments of relatively short duration, ranging from $1-6$ days at $40^{\circ} \mathrm{C}$ followed by a return to $30^{\circ} \mathrm{C}$, and longer periods of time at a constant $40^{\circ} \mathrm{C}$. It was found that four effects on chiasma frequency could be produced. In addition to the major reduction in chiasma frequency reported earlier, a second small period of reduction was obtained. The other two effects involved increases in chiasma frequency. Three of these effects, the two decreases and one increase, were produced following heat-treatments of meiotic prophase stages, after premeiotic DNA synthesis was completed. The other increase was obtained following heat-treatment of spermatogonia. The possible nature of these effects is discussed. It is suggested that the late prophase period, during which a small increase in chiasma frequency (called Effect 1) is produced by heat-treatments, could correspond to at least part of the time during which chiasmata form.

\section{INTRODUCTION}

A constant sublethal temperature of $40^{\circ} \mathrm{C}$ greatly affects the course of male meiosis in the desert locust Schistocerca gregaria. Such treatment leads to a progressive reduction in chiasma frequency, with univalent production, and an accompanying tendency for the distal localisation of those chiasmata which are formed (Henderson, 1962, 1963a). These effects of high temperature are not expressed immediately, however: a great reduction in the number of chiasmata formed does not occur until the locusts have spent some 5-6 days at a constant $40^{\circ} \mathrm{C}$. This initial lag of several days could be interpreted in one of two ways: either (a) there is no very great immediate effect of the heat-treatment and it is only after several days that the cumulative damage is sufficiently great to lead to a modification of the processes involved in chiasma formation, or (b) there is an immediate, or relatively rapid, effect at some sensitive stage, but it takes several days' cellular development before the effect becomes visible at diplotene, diakinesis and metaphase I stages.

That the latter possibility is correct was demonstrated in some preliminary experiments, in which locusts were heat-treated for only 2 days at $40^{\circ} \mathrm{C}$, after which they were returned to $30^{\circ} \mathrm{C}$. The 2 day heat-shock irreparably modified the chiasma properties of cells which were at the sensitive stage when treated and a pulse of cells possessing reduced chiasma frequencies passed through meiosis a week later. This discovery, together with the previous observations on the effects of a constant $40^{\circ} \mathrm{C}$ made it possible to determine the time of this heat-sensitive stage in relation to the time of premeiotic DNA synthesis. Experiments of these two types were carried out with individuals which had been injected with ${ }^{3} \mathrm{H}$-thymidine at the start. Autoradiography of labelled chromosomes showed that this heat-sensitive period occurred in early meiotic prophase nuclei, soon after the main pre-meiotic $S$-period of DNA synthesis was completed (Henderson, 1966). I suggested at the time that this major reduction in chiasma frequency obtained might not result from a direct action of the elevated temperature on the processes involved in chiasma formation themselves, but could involve an effect on some aspect of the completeness of efficiency of chromosome pairing.

In my earlier experiments, using relatively outbred material supplied by the Anti-Locust Research Centre, London, there was considerable heterogeneity in the response to heat-treatment 
(Henderson, 1962, 1963a). This was likely to have been caused, at least in part, by genetic variation within the material. To reduce this variability and to permit more precise study of the effects of heattreatments on chiasma formation, I have been inbreeding Schistocerca for many years. Using this material, further analyses have now been made of the effects of heat-treatments of relatively short duration (1-6 days), followed by a standard control temperature of $30^{\circ} \mathrm{C}$. These experiments have shown that the single major effect, referred to above, is not the only effect of heat-treatments: four separate effects can sometimes be produced. Two of these involve increases in chiasma frequency and two involve decreases. In analysing the data the contributions made to each of these effects by the different sized chromosomes within the complement have been assessed.

\section{MATERIALS AND METHODS}

The locusts used were inbred in the Genetics Department, Cambridge, using predominantly sib matings, from previously inbred material kindly supplied by the Anti-Locust Research Centre, London (see John and Naylor, 1961, for details of this culture). They were reared in a diurnally fluctuating temperature of approximately $25^{\circ} \mathrm{C}$ night and $30^{\circ} \mathrm{C}$ day, with an automatically controlled photoperiod of 10 hours. This was provided partly by fluorescent strip lighting and partly by lamp bulbs in individual cages. They were fed daily with freshly germinated wheat seedlings.

The experimental procedure was similar to that which has been described before (Henderson, $1962,1963 a$ ). Young male adults, within a week of moulting were placed in $15^{\prime \prime} \times 8^{\prime \prime}$ ventilated cylindrical containers. They were heat-treated in an unlighted incubator maintained at $40^{\circ} \mathrm{C}$. At the end of the treatment some were transferred to a different incubator kept at $30^{\circ} \mathrm{C}$. In each experiment, to reduce the amount of variation to a minimum, care was taken to use young male adults, preferrably sibs, of as similar age as possible, and to randomise individuals reared in different cages. Daily sampling involved a precise 24 hour period.

In different experiments, two or more individuals were taken on each day sampled, and their testes removed by vivisection. After removing the enveloping fat body the testes were fixed in $1: 3$ acetic alcohol. Chiasma frequencies in each of the three size groups recognised ( $\mathrm{L}, \mathrm{M}$ and $\mathrm{S}$ ) were scored in 20 cells from each individual in propionic-orcein squash preparations. Chiasmata were scored at diplotene when frequencies were high and at metaphase I when very low (see Henderson, 1962, 1963a for reasons). Terminalisation does not occur in this species. Means, variances, sample standard deviations and standard errors were calculated.

The inbred nature of the material, with low between-individual variation, made it unnecessary for detailed control series to accompany every experiment carried out. One main control series was provided for the long experiments, using daily sampling over a two week period at a constant $30^{\circ} \mathrm{C}$ (fig. 6). This showed no great effect of age or day-to-day fluctuations in chiasma frequency. Several of the individuals to be used in each of the heat-treatment experiments were fixed and scored to confirm thay they corresponded with these control values. A second control series was run alongside the shorter experiment carried out to delimit the magnitude and duration of Effect 1. This involved daily sampling over one week at a constant $30^{\circ} \mathrm{C}$ (fig. 8).

\section{RATIONALE}

These experiments were originally carried out to determine more about the nature of the major decrease in chiasma frequency previously studied in some detail. To this end, two different sets of experiments were carried out. These, and their initial purpose, were as follows: (a) the effects of a constant $40^{\circ} \mathrm{C}$ to re-define the effects in the present material; (b) the effects of shorter duration heat-treatments of 3,2 and 1 days at $40^{\circ} \mathrm{C}$, to determine (i) the magnitude and duration of the effects produced by shorter heat-shocks, (ii) the shortest period at $40^{\circ} \mathrm{C}$ that would produce an effect (iii) to confirm $Q_{10}$ calculations made earlier using radioisotopes and (iv) to determine whether any effects could be produced by shorter heattreatments which were not so readily demonstrable at a constant high temperature.

When it was discovered, from the short heattreatment experiments, that there was a strong possibility of three other effects being produced, in addition to the major reduction obtained before, further experiments were carried out. These involved $2,2 \frac{1}{4}$ and 6 days at $40^{\circ} \mathrm{C}$, with sampling designed to test the reality and nature of these new effects.

To facilitate the description of the experimental results, these four effects will first be listed. They are numbered, for simplicity, Effects 1-4. Effects 1 and 4 involve increases in chiasma frequency, 
while Effects 2 and 3 involve decreases. From a joint consideration of the present experiments and the autoradiographic studies mentioned earlier (Henderson, 1966) it is possible to deduce their positions in the meiotic sequence. This is shown in fig. 1 where the relative durations of each meiotic stage is indicated by its extent along the horizontal axis. Three of the effects may be produced if the temperature shock is given after the main period of premeiotic DNA replication (S); the other is found when the temperature shock is given prior to this time of DNA synthesis.

\section{RESULTS}

The effects of heat-treatments of different duration on overall cellular chiasma frequency

Effects of a constant $40^{\circ} \mathrm{C}$. The chiasma frequency response obtained when 32 individuals were subjected to a constant $40^{\circ} \mathrm{C}$ is shown in fig. 2(a). Whereas in the experiments reported in 1963 a consistent reduction in chiasma frequency to near zero was not obtained until the 16 th day at $40^{\circ} \mathrm{C}$, the present material was rather more sensitive to the heat-treatment, and showed a relatively uniform response of almost total univalence after the initial 5-6 day lag. This reduction, termed Effect 3 , was preceded by a small decrease (Effect 2), but Effect 1 was not shown in this experiment. The tendency for eventual "recovery" was seen to begin by days 14-16 and was not delayed until days $17-18$ as in the 1962 experiments. The overall response was thus rather different from that described earlier. It was similar, however, in the essential points that:

(a) there was a major reduction in chiasma frequency, followed by the tendency for recovery.

(b) the onset of this great reduction appeared after an initial 5-day lag.

(c) the pattern of response within the complement was more or less identical to that obtained before. This applied both to the distribution of chiasmata between homologous chromosomes of different length and to the pattern of localisation observed.

Effects of 3 days at $40^{\circ} \mathrm{C}$. The results obtained when 36 individuals were subjected to 3 days at $40^{\circ} \mathrm{C}$ are provided in fig. $3(\mathrm{a})$. Effect 1 was again not shown in this experiment, while Effect 2 involved a spreading reduction in chiasma frequency, extending from day 4 onwards, merging with Effect 3 . Effect 3 itself was very pronounced. It led to a complete reduction in chiasma frequency on day 9 , both individuals sampled on this day showing almost total univalence. Thereafter, recovery was rapid, followed by Effect 4-an increase in chiasma frequency, so that individuals sampled on days 15,16 and 17 came to possess more than the control mean of 19.69 chiasmata per cell. These small increases in mean chiasma frequency per cell per individual entailed fairly great increases in maximum chiasma frequencies per cell, the maximum being raised from the 23-24 of control cells to 26, 27 and even 28. The spermatocytes possessing these higher chiasma frequencies often tended to be rather smaller than normal, control cells. The significance of this will be raised in the discussion.

Effects of 2 days at $40^{\circ} \mathrm{C}$. This experiment involving 30 individuals gave the first clear overall picture of the 4 effects of high temperature treatment on chiasma frequency (fig. 4(a)). An initial small increase in chiasma frequency was seen on day 3 (Effect 1) followed by a slight decrease on day 4 (Effect 2). After this, chiasma frequencies returned towards the control mean for days 5, 6 and 7. The second, and major, reduction (Effect 3 ) with univalent formation, was found on days 8,9 and 10 . Because Effect 2 is here separated from Effect 3 by several days it is thus more clearly recognisable as a discrete effect than in the previous experiment. After recovery, on days 12-15 there was again an increase in chiasma frequencies (Effect 4). The increase found here was slightly larger than that obtained in the 3-day heat-treatment experiment.

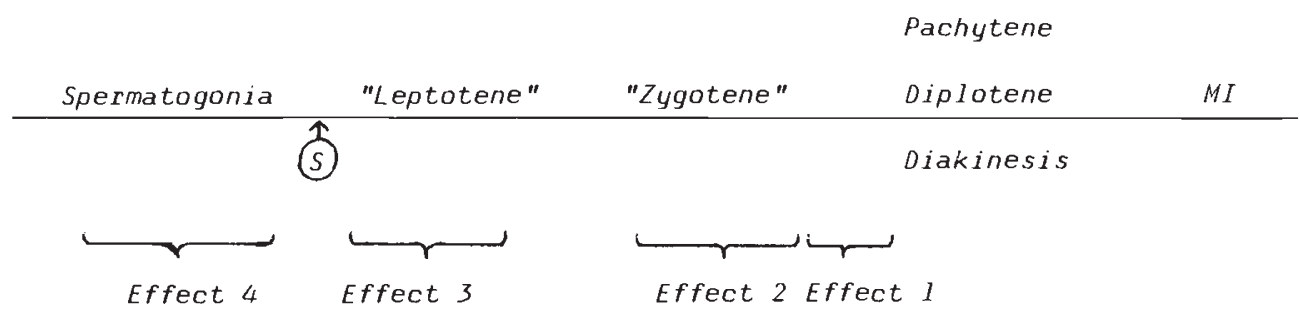

Figure 1 The positions of the four effects of heat-treatment on chiasma frequency in relation to the meiotic or premeiotic stage affected. 


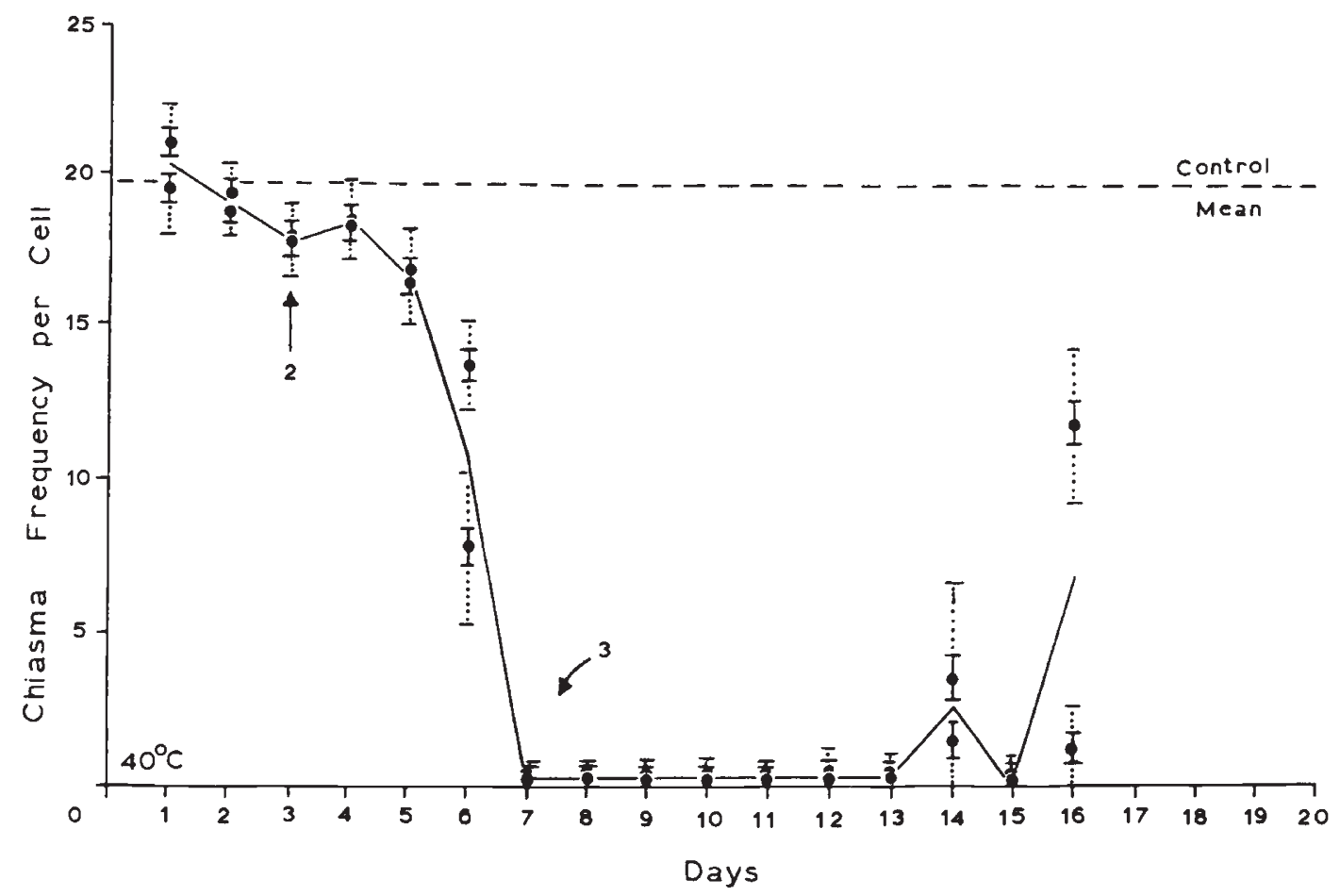

(A)

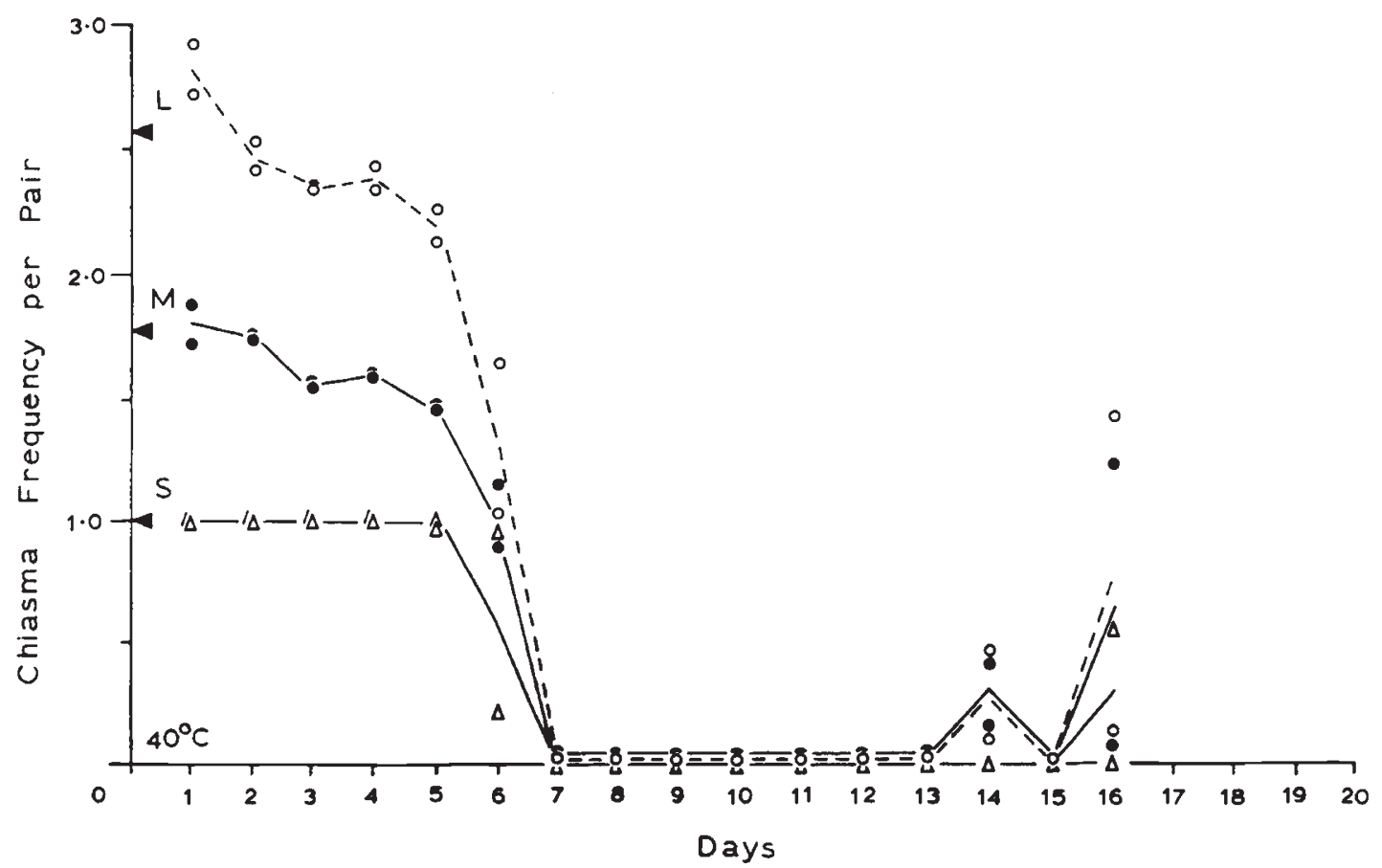

(B)

Figure 2 Chiasma frequency response with time at a constant $40^{\circ} \mathrm{C}$. (A) means and standard errors of 20 cells scored from each of the two individuals sampled per day. Overall control mean dotted. Positions of Effects 2 and 3 indicated. (B) the response within the 3 size groups ( $\mathrm{L}, \mathrm{M}$ and $\mathrm{S}$ ). 


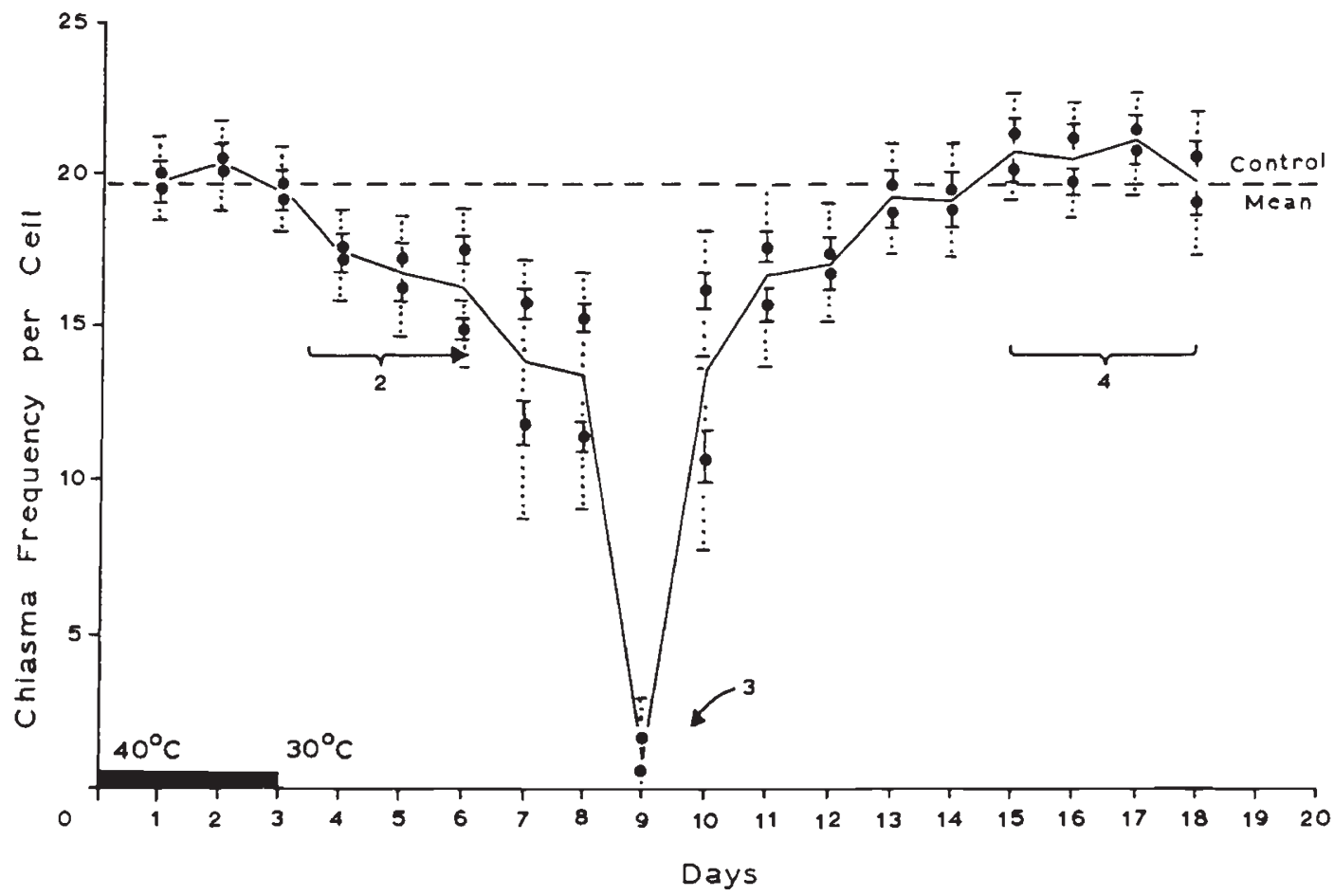

(A)

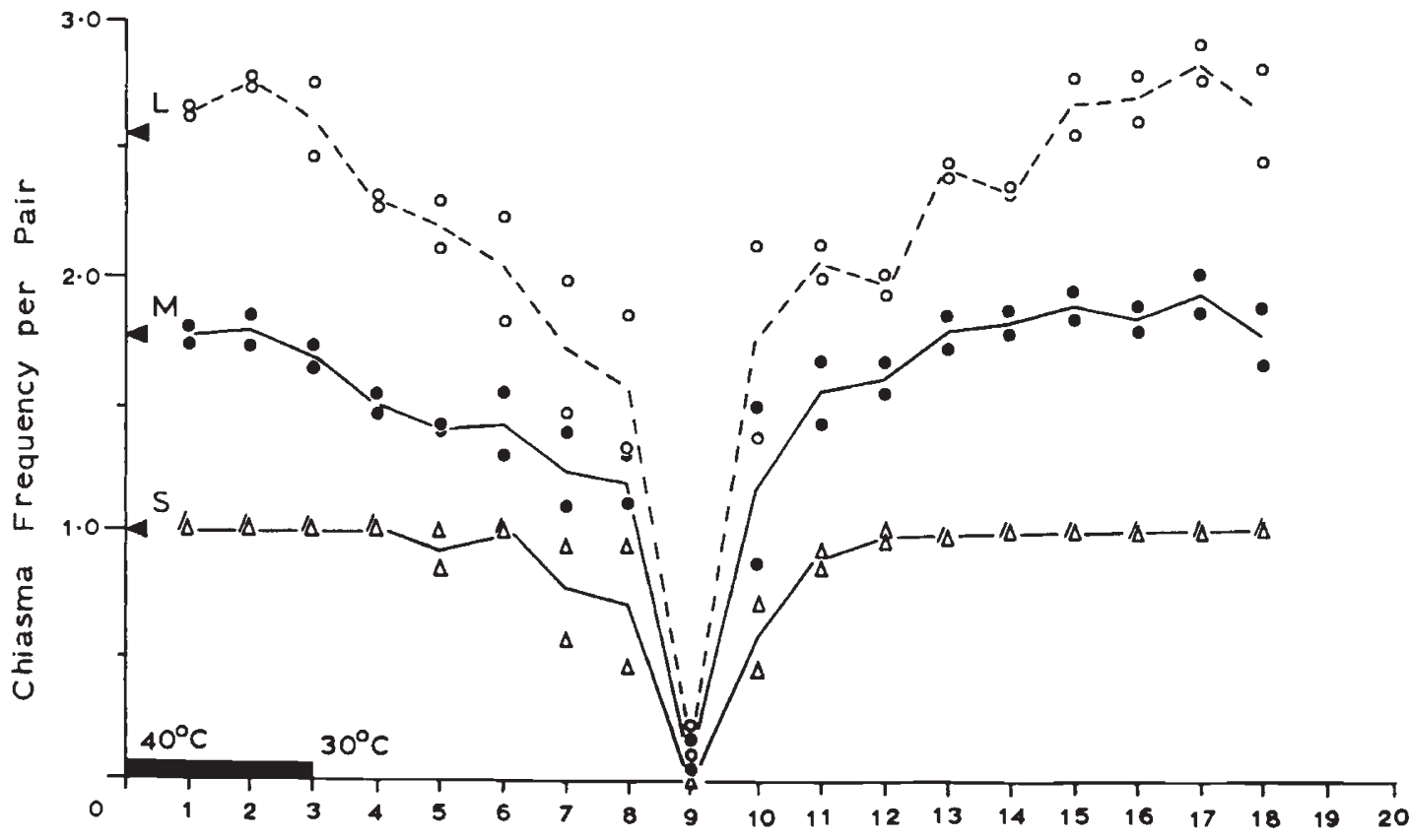

Days

(B)

Figure 3 Chiasma frequency response with time following heat-treatment at $40^{\circ} \mathrm{C}$ for 3 days followed by a return to $30^{\circ} \mathrm{C}$. (A) means and standard errors of 20 cells scored from each of the two individuals sampled per day. Positions of Effects 2,3 and 4 indicated. (B) the response within the 3 size groups ( $L, M$ and $S$ ). 


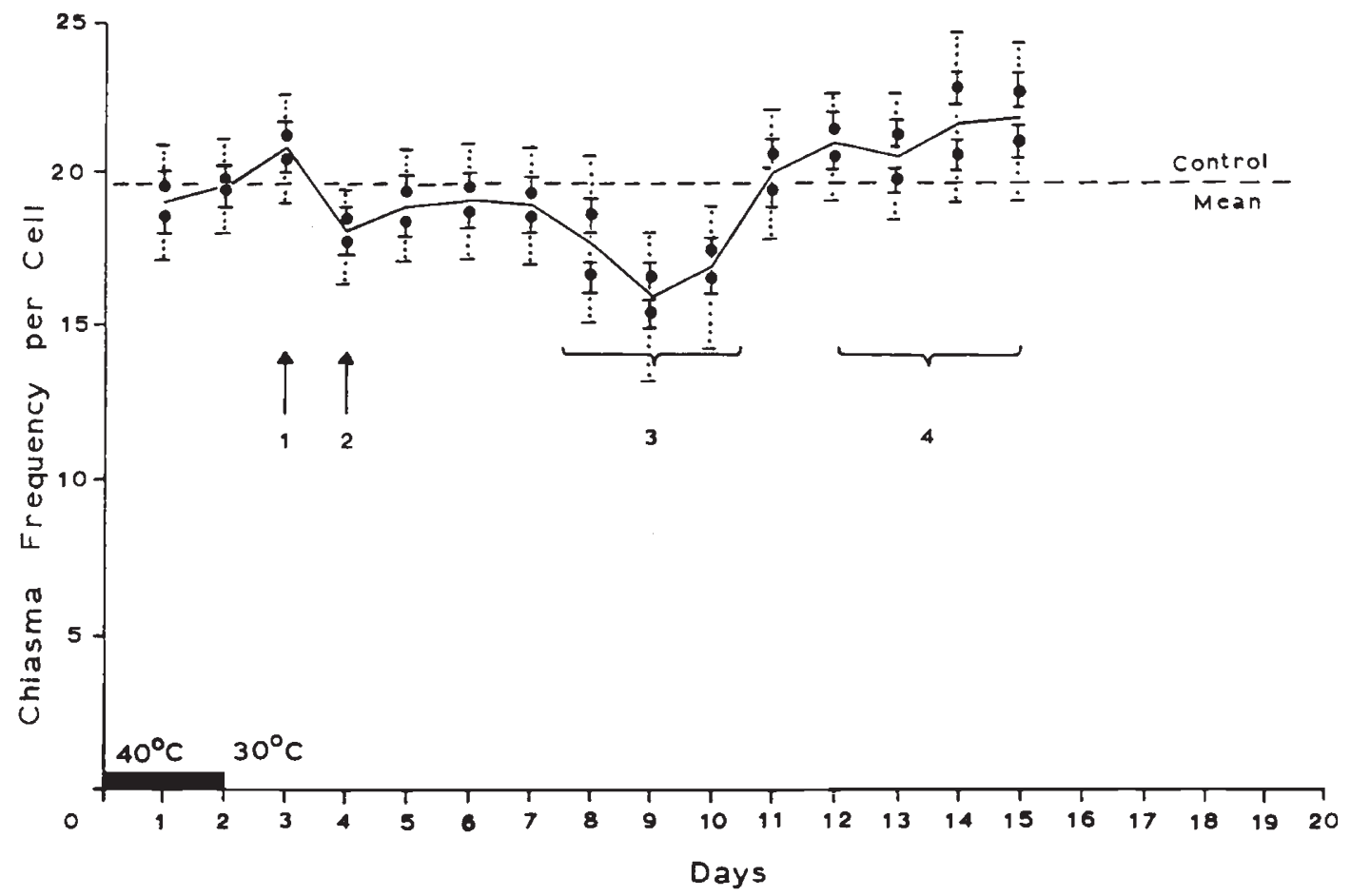

(A)

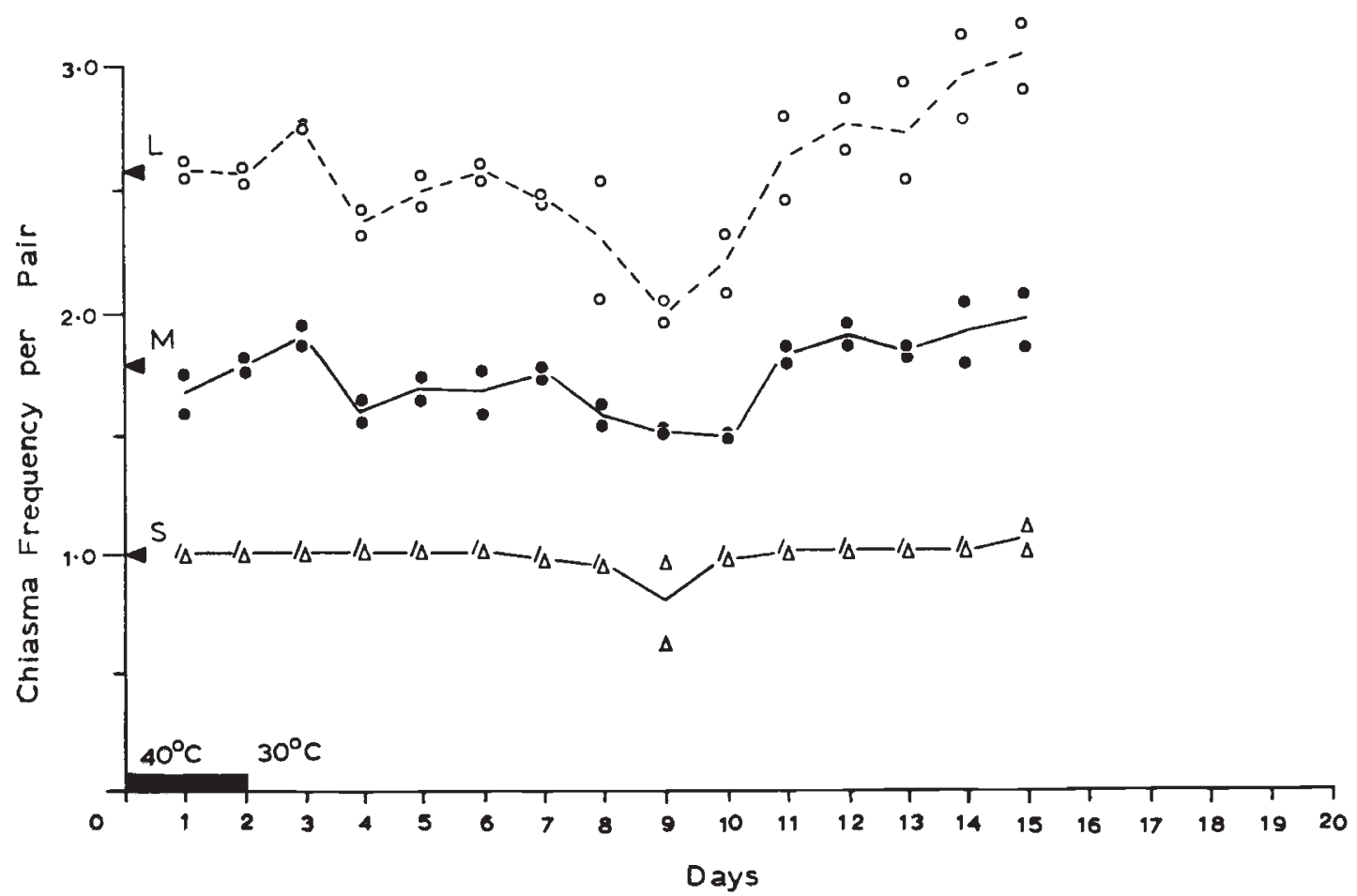

(B)

Figure 4 Chiasma frequency response with time following heat-treatment at $40^{\circ} \mathrm{C}$ for 2 days followed by a return to $30^{\circ} \mathrm{C}$. (A) means and standard errors of 20 cells scored from each of the two individuals sampled per day. Positions of Effects $1,2,3$ and 4 indicated. (B) the response within the 3 size groups (L, M and S). 
Effects of 1 day at $40^{\circ} \mathrm{C}$. The chiasma frequencies of 30 individuals treated for 1 day at $40^{\circ} \mathrm{C}$, followed by a return to $30^{\circ} \mathrm{C}$, are shown in fig. $5(\mathrm{a})$. It can be seen that even 1 day's heat-treatment led to the manifestation of all four effects, although Effect 3 was small. An initial slight increase on day 4 (Effect 1) and decrease on day 5 (Effect 2) was followed by the second decrease (Effect 3 ) on days 8-9 and, on day 15, the second increase (Effect 4). Effect 3 did not here involve a great reduction in the mean chiasma frequency per cell, but some effect was produced at this time, involving a tendency for the terminal siting of some chiasmata and the production of a few univalents. It is clear, however, that the effect is not a very large one and that one day at $40^{\circ} \mathrm{C}$, out of the 12-13 day period between $S$ and metaphase $\mathrm{I}$, is approaching the minimum period of time likely to produce much effect at this stage of prophase.

Effects 1 and 2 further analysed. The three experiments described above, involving heat-treatments of relatively short duration, produced evidence suggesting that chiasma frequencies could be affected by high temperature in later stages of prophase than had been demonstrated before. Although these effects were slight, of short duration and involved only a few individuals in the 1 and 2 days at $40^{\circ} \mathrm{C}$ heat-treatment experiments, the low between-individual variation in these experiments and hence the close repeatability of the chiasma frequencies of the two individuals sampled on any one day, suggested that one could place greater reliance on the implications of these small effects than one would have done if one were using stocks of greater variability. The absence of an Effect 1 increase in the experiments using longer heat-treatments could be due to a number of possibilities, including: (a) the longer heat-treatment may suppress it, (b) it may be shorter than 1 day in duration and may be missed in a 1 day sampling programme, particularly at the high temperature, (c) there may be between-individual variation in the expression of the effect and it might sometimes be missed if only two individuals are sampled on each day.

To investigate these possibilities a number of further experiments were carried out. The most revealing of these involved a heat-treatment of 2 days at $40^{\circ} \mathrm{C}$, using a 12-hourly sampling programme, to detect effects which might be missed with 24-hourly sampling. In this experiment 28 individuals were incubated for 2 days at $40^{\circ} \mathrm{C}$ and then returned to $30^{\circ} \mathrm{C}$. Two individuals were sampled every 12 hours for a total period of 6 days.
A control series was maintained in the same incubator at $30^{\circ} \mathrm{C}$ and sampled on a daily basis to provide a close comparison with the experimental animals. The results, shown in fig. 7(a) confirm the reality of Effect 1 and show that it is indeed of short duration. It can be seen from this figure that the brief increase, of approximately 1 day's duration, raised chiasma frequencies from the control mean of just under 20 chiasmata per cell to a value of just below 22 chiasmata per cell, an increase of circa 10 per cent. Following this short, sharp increase, a spreading decrease was obtained (Effect 2 ) from 4.5 days onwards. Both effects were statistically significant departures from the control values.

Effects 3 and 4 further analysed. In the 2 and 3 day heat-treatment experiments, clearcut increases in chiasma frequencies (Effect 4) were obtained after individuals recovered from the sharp decreases associated with Effect 3 . These increases raised mean chiasma frequencies up to 5-10 per cent above control mean values. However, to determine more about the nature, magnitude and duration of Effect 4 a further experiment was carried out. For this a period of 6 days at $40^{\circ} \mathrm{C}$ was chosen, as this corresponds to the time taken for one whole generation of spermatocytes to pass through from $S$ to metaphase I (Henderson, 1966). In this experiment, a total of 45 individuals was subjected to this treatment. Sampling was not carried out during the first 5 days at $40^{\circ} \mathrm{C}$ as this was well documented in earlier experiments. From day 6 onwards, two individuals were sampled on most days, but when Effect 4 was beginning, on days 17, 18 and 19, one or two additional individuals were taken (fig. 9(a)).

The results confirmed and extended all that had been found before of the action of $40^{\circ} \mathrm{C}$ heattreatments on both Effect 3 and Effect 4. Following the return to $30^{\circ} \mathrm{C}$ at the end of day 6 , chiasma frequencies fell to almost total univalence. Because of the slower rate of cellular development at $30^{\circ} \mathrm{C}\left(Q_{10}=2 \cdot 3\right.$, Henderson, 1966), this was not obtained until day 9 , which corresponds exactly with the time of day 7 at a constant $40^{\circ} \mathrm{C}$ found in the first experiment with this inbred material (fig. 2(a)). The 6 days' heat-treatment was responsible for chiasma frequencies remaining close to zero for a total of 5 days at $30^{\circ} \mathrm{C}$ (days 9-13) after which a smooth return to control levels was found. The control mean was reached on day 18 . Thereafter, between days 18 and 24 a broad increase in chiasma frequencies was obtained, corresponding to Effect 4 . The mean increase was approximately 10 per cent of control mean values, but the maximum chiasma frequency per cell was often as 


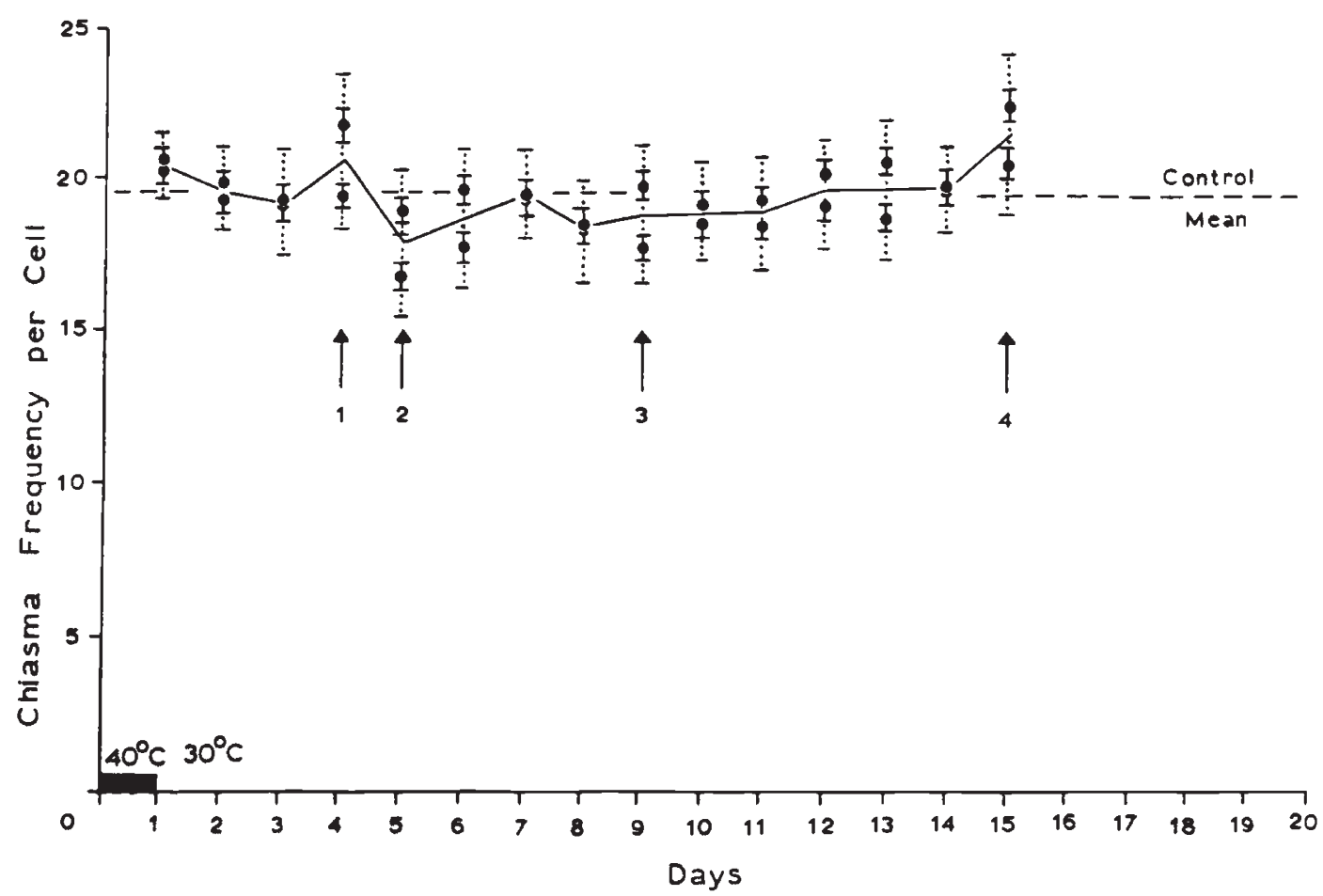

(A)

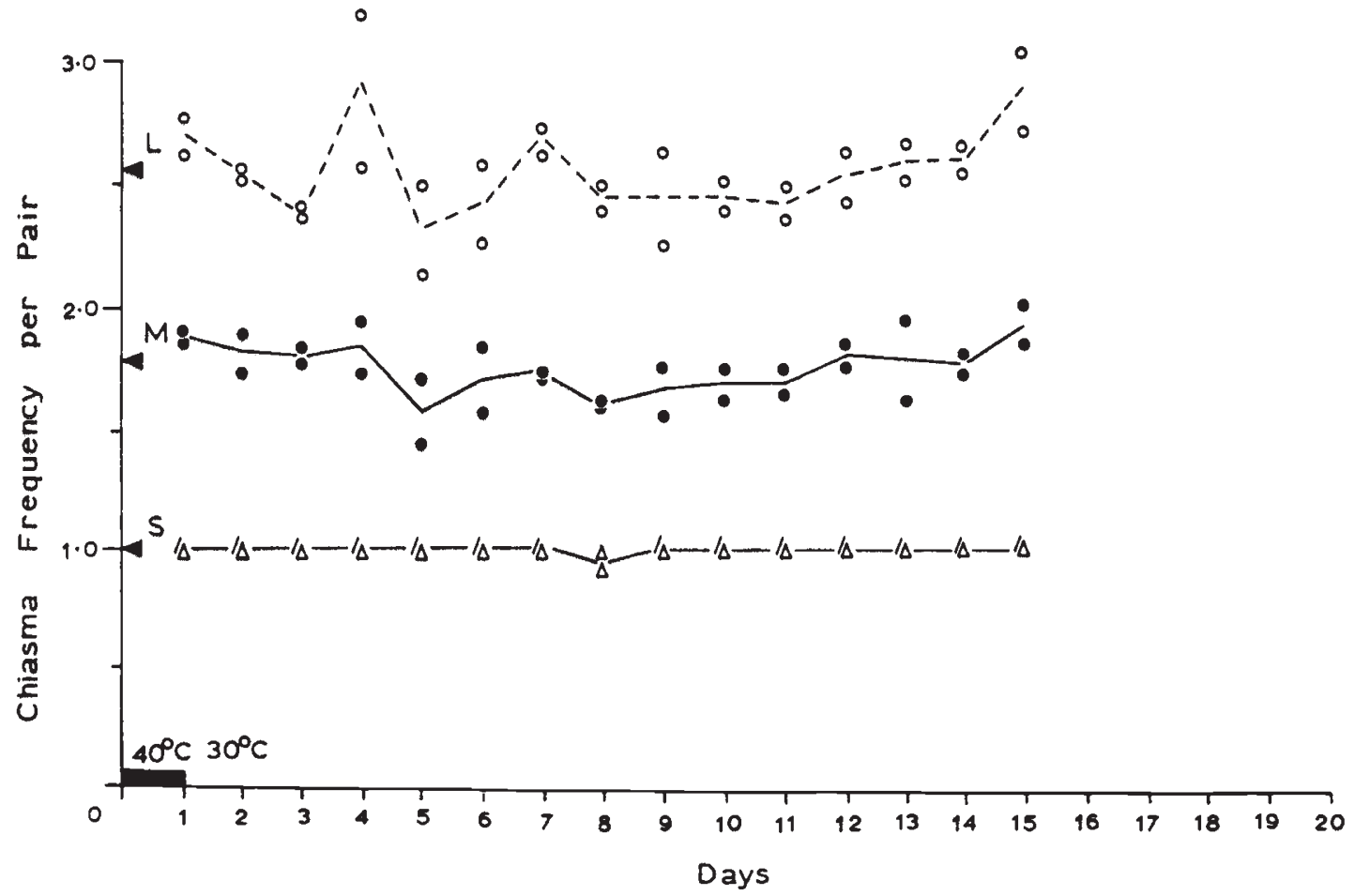

(B)

Figure 5 Chiasma frequency response with time following heat-treatment at $40^{\circ} \mathrm{C}$ for 1 day followed by a return to $30^{\circ} \mathrm{C}$. (A) the means and standard errors of 20 cells scored from each of the two individuals sampled per day are provided. Positions of Effects 1, 2, 3 and 4 indicated. (B) the response within the 3 size groups (L, M and S). 


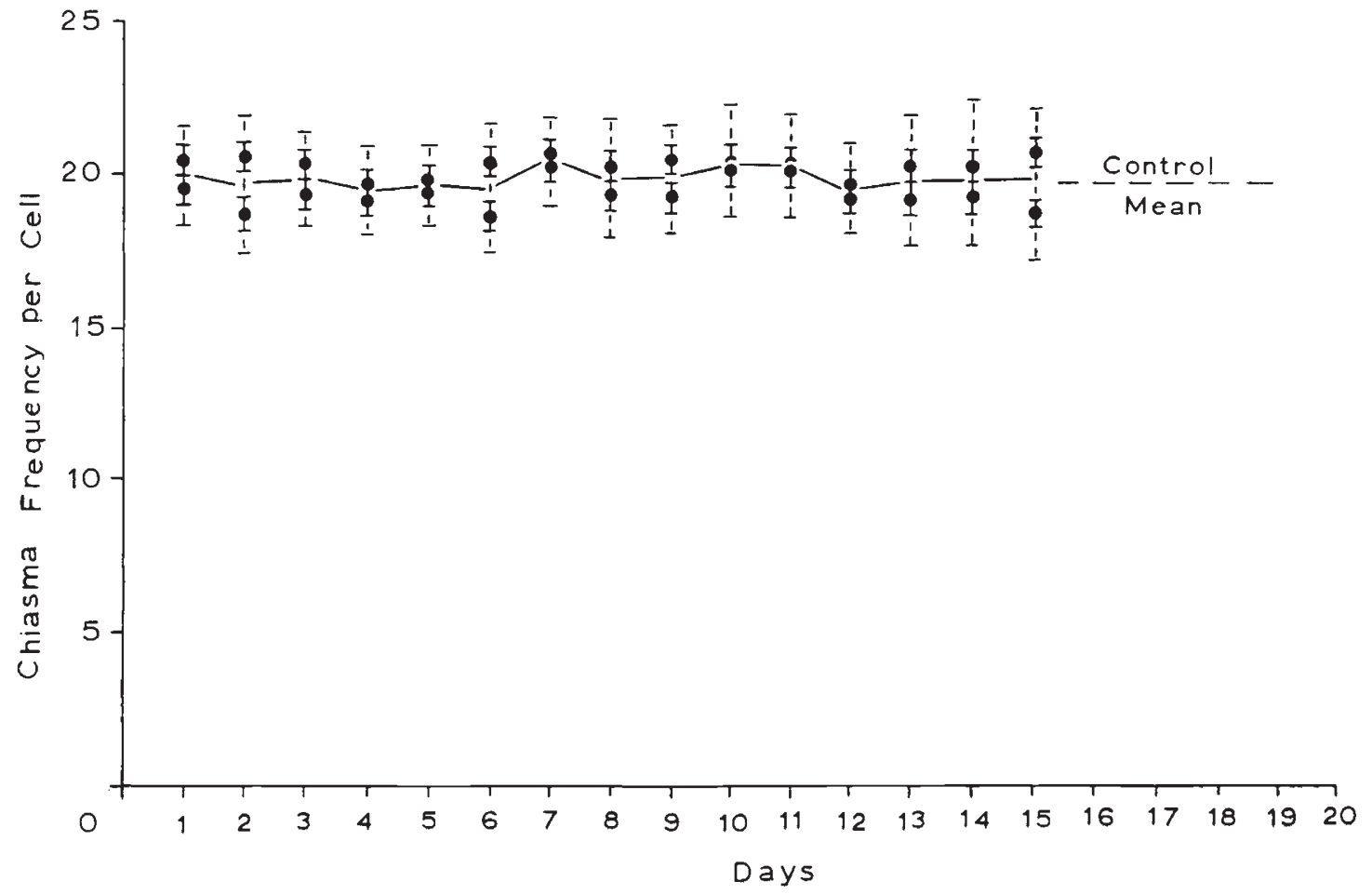

Figure 6 Chiasma frequency response with time shown by 30 control individuals maintained at a constant $30^{\circ} \mathrm{C}$. The means and standard errors of 20 cells scored from each of the two individuals sample per day are provided.

high as 28 , with even the small chromosomes within the complement commonly forming two chiasmata. On days 25 and 26 mean chiasma frequencies returned to control levels.

\section{The response throughout the complement}

In order to obtain the maximum amount of information possible on these 4 effects of heat-treatment on chiasma frequency, the chiasma and univalent frequencies of the 3 main size groups within the complement (3 large (L), 5 medium (M) and 3 small (S) chromosomes were recorded separately for all 230 of the experimental individuals scored. Summary graphs below each of the mean chiasma frequency graphs reveal the contributions of each size group to each of the effects found. To avoid duplication, the response during each effect will be described, rather than dealing with each experiment individually.

Effect 1. It will be seen from figs 4(b), 5(b) and 7 (b) that the increase obtained during Effect 1 was mainly brought about by the longer members of the complement. Both $\mathrm{L}$ and $\mathrm{M}$ chromosomes were involved, the former more so than the latter, but the small ( $\mathrm{S}$ ) chromosomes did not form more than their usual 1 chiasma.

Effect 2. Here again, the longest members of the complement were responsible for the decreases found (figs 3(b), 7(b)). Both $\mathrm{L}$ and $\mathrm{M}$ chromosomes contributed substantially to the decreases, while the $\mathbf{S}$ chromosomes usually retained their single chiasma. However, with the more prolonged heat-treatment of 3 days at $40^{\circ} \mathrm{C}$, the $S$ chromosomes did become involved in the spreading Effect 2 which merged with Effect 3 (fig. 3(b)). As the $S$ chromosomes usually form only one chiasma, reduction in chiasma frequency for this size group automatically leads to the production of univalents and small numbers of $S$ univalents were found on days 3,4 and 5 in this experiment.

Effect 3. As described in the earlier publications of this series (Henderson, 1962, 1963a) all chromosomes within the complement become involved during this period of widespread reduction in chiasma frequency. The patterns of chiasma and univalent distribution shown by the three size groups, at all levels of chiasma and univalent frequencies, were more or less identical in the 


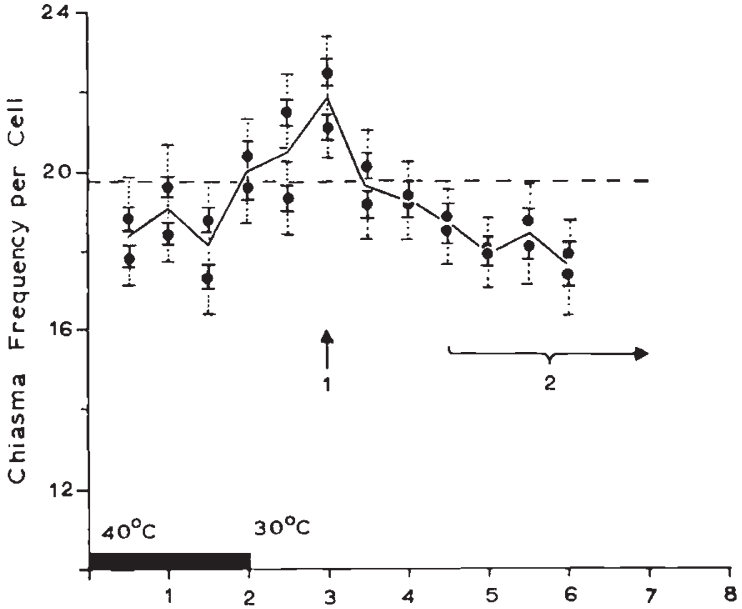

(A)

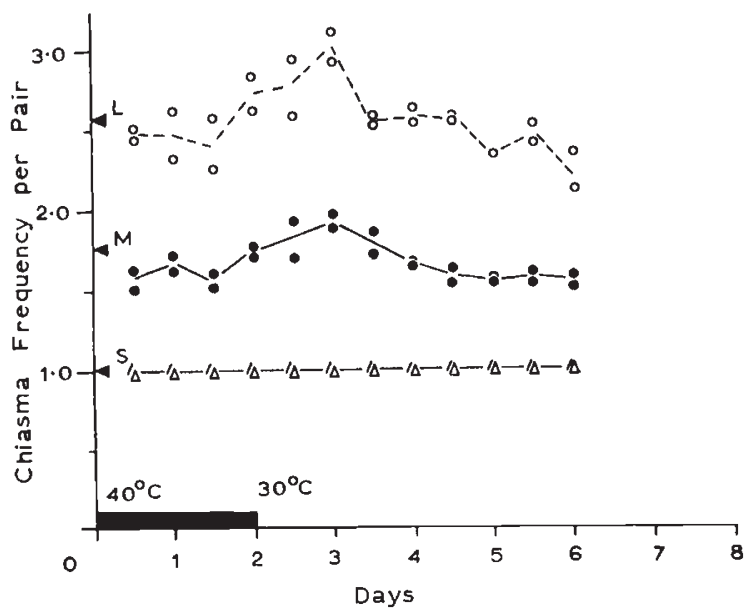

(B)

Figure 7 Chiasma frequency response with time following heat-treatment at $40^{\circ} \mathrm{C}$ for 2 days followed by a return to $30^{\circ} \mathrm{C}$. (A) the means and standard errors of 20 cells scored from each of the two individuals sampled every twelve hours during the first 6 days are provided, to delimit Effects 1 and 2. (B) the response, with twelve-hour sampling, within the 3 size groups ( $L, M$ and $S$ ).

present inbred material to those described before and will not be re-described here. Of particular interest and importance, however, is the comparison which could be made, in the present experiments, between the distributions of chiasmata and univalents during the onset of Effect 3, as chiasma frequencies were falling towards zero and the pattern of distribution as chiasma frequencies were rising again from low levels, back towards control values. When both chiasma frequency/ chromosome length graphs were plotted (fig. 10(a),

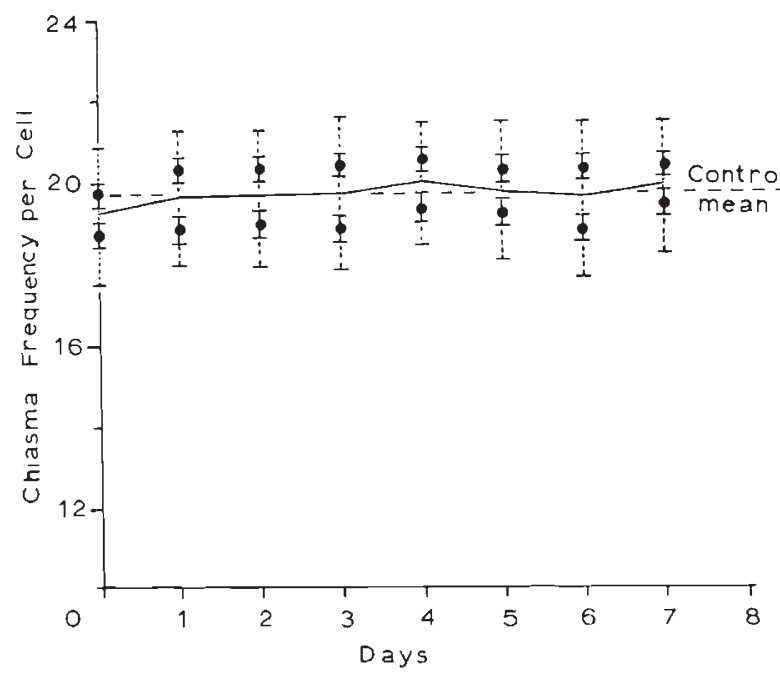

Figure 8 Chiasma frequency response with time shown by 16 control individuals maintained at a constant $30^{\circ} \mathrm{C}$ for comparison with fig. 7(A). The means and standard errors of 20 cells scored from each of the two individuals sampled per day are provided.

(b)) and univalent number histograms were prepared (figs 11,12 ) it was seen that the chiasma and univalent distributions, at any one chiasma frequency level, were more or less identical during periods of increase or decrease. This finding is of some interest when hypotheses of the mechanisms underlying chiasma distribution are being considered.

Effect 4. During the expression of Effect 4, all chromosomes within the complement could be seen to be involved in the increase (figs 3(b), 4(b), $9(\mathrm{~b}))$. This even involved the small $S$ chromosomes, which could occasionally, and in some individuals commonly, form more than one chiasma (figs 9(b), 10(b)). However, the greatest contribution was clearly made, as might be expected, by the longest members of the complement. The normal pattern of chiasma interference did not always appear to be operating in cells showing this effect, for close "bunching" of chiasmata could sometimes be obtained, in contrast with the more uniform, equidistant spacing which characterises control cells (Henderson, 1963b). In control individuals the chromosome length/chiasma frequency relationship is not linear, nor a simple curvilinear relationship, but rather sigmoidal (Henderson, 1963b). At the height of Effect 4, however, the greater increases shown by the longer members of the complement, and the longer $\mathbf{S}$ chromosomes, makes the relationship very closely linear (fig. 10(b)). 

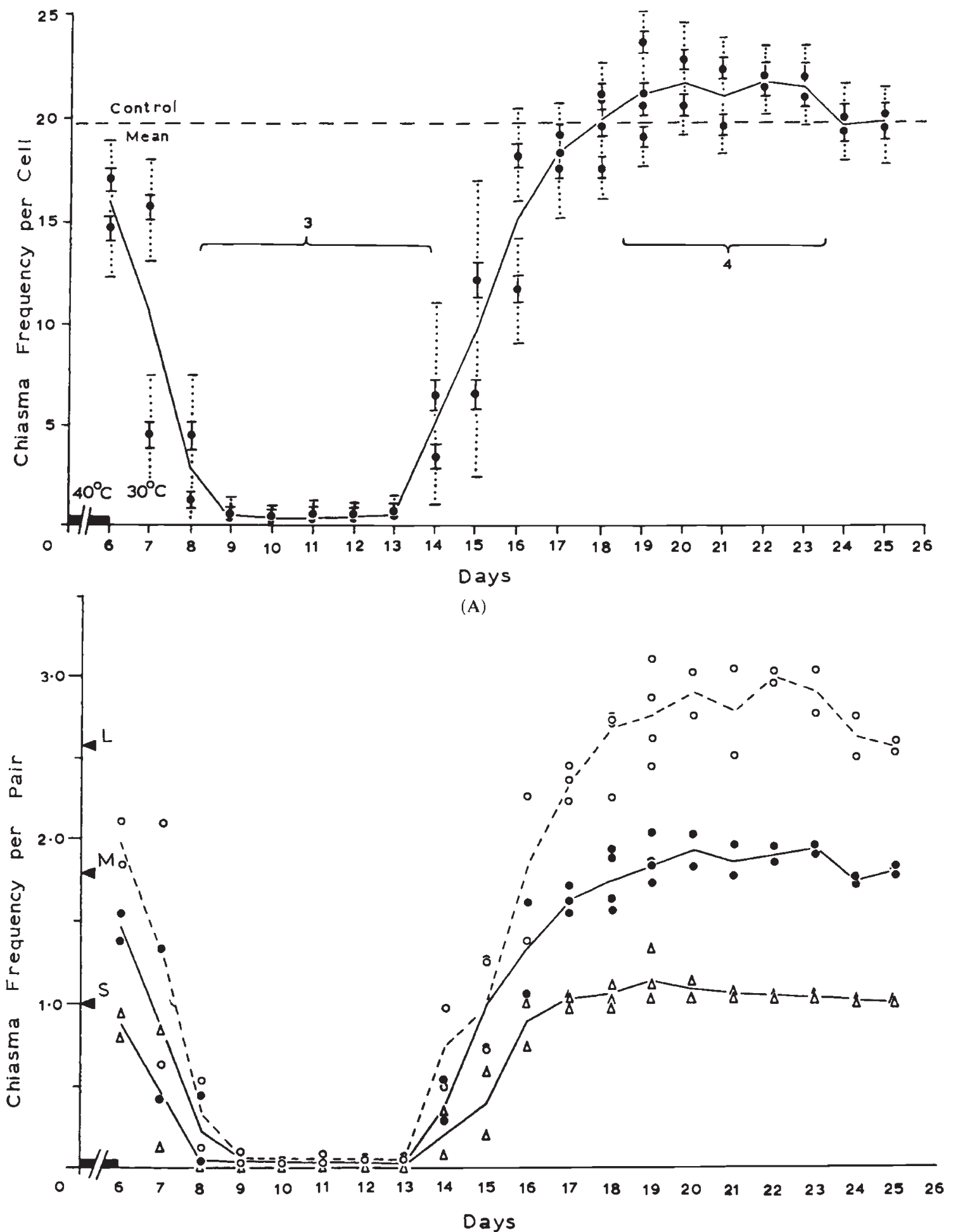

(B)

Figure 9 Chiasma frequency response with time following heat-treatment at $40^{\circ} \mathrm{C}$ for 6 days followed by a return to $30^{\circ} \mathrm{C}$. (A) the means and standard errors of 20 cells scored from each of the two or three individuals sampled per day are provided. Positions of Effects 3 and 4 indicated. (B) the response within the 3 size groups ( $L, M$ and S). 


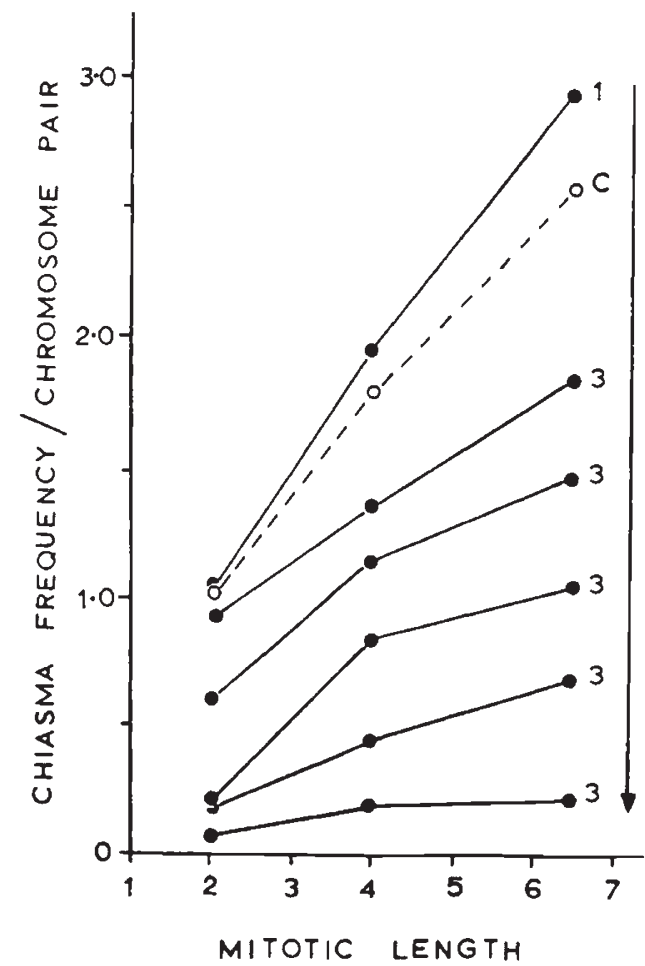

(A)

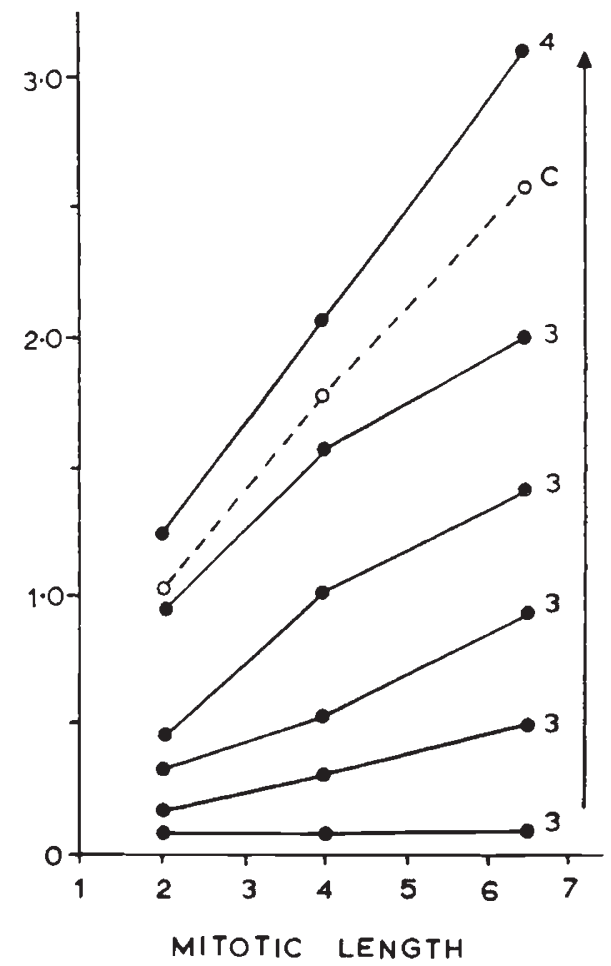

(B)

Figure 10 (A) and (B). Selected mean chromosome length/chiasma frequency curves for the three size groups recognised (L, M and $S$ ) at all levels of chiasma frequency. The distribution of chiasma frequencies throughout the complement is illustrated in control curves (C), in individuals showing the increase called Effect 1 (1) and Effect 4 (4) and in individuals showing the large decrease called Effect 3 (3). (A) shows the pattern during Effect 3 as chiasma frequencies fall. (B) shows the pattern as chiasma frequencies rise.

\section{DISCUSSION}

The autoradiographic demonstration that the major reduction in chiasma frequency brought about by $40^{\circ} \mathrm{C}$ heat-treatment is due to an effect on chromosomes a day or so after they have completed their main period of premeiotic DNA synthesis (Henderson, 1966) revealed that the time of chiasma formation must be separated from the main premeiotic synthesis of DNA by at least this time interval. It did not, however, show that the time of chiasma formation coincided with this heat-sensitive period, nor that the effect observed was a direct one on the processes involved in chiasma formation themselves. Indeed, from a comparison of chromosome behaviour in heattreated and control material, I concluded that this effect was more likely to be an effect on the completeness or efficiency of the pairing processes which precede chiasma formation. This would, in turn, lead to a reduction in chiasma frequency, for clearly chiasma formation must depend upon the nature of preceding synapsis. Because both asynapsis and desynapsis could be seen to be induced by high temperature treatment, the use of the noncommittal term "univalence" was recommended, to indicate the presence of univalents during the first meiotic division (Henderson, 1962).

The time of this effect, soon after DNA synthesis is complete, in leptotene/zygotene nuclei, prior to the long main zygotene stage (see page 389 ), also adds support to the interpretation that an effect on synapsis is involved. Further confirmation comes from the results of the present experiments, which demonstrate four effects of heat-treatments, two of which arise following treatments applied at the end of the late zygotene/early pachytene stage, several days later than the previous heat-sensitive period, and corresponding to a far more likely time of chiasma formation in meiotic prophase. The four effects are most readily seen from experiments involving heat shocks of 2 days at $40^{\circ} \mathrm{C}$ (fig. $\left.4(\mathrm{a})\right)$. A slightly simplified representation of the effects of a 2 day heat shock on 

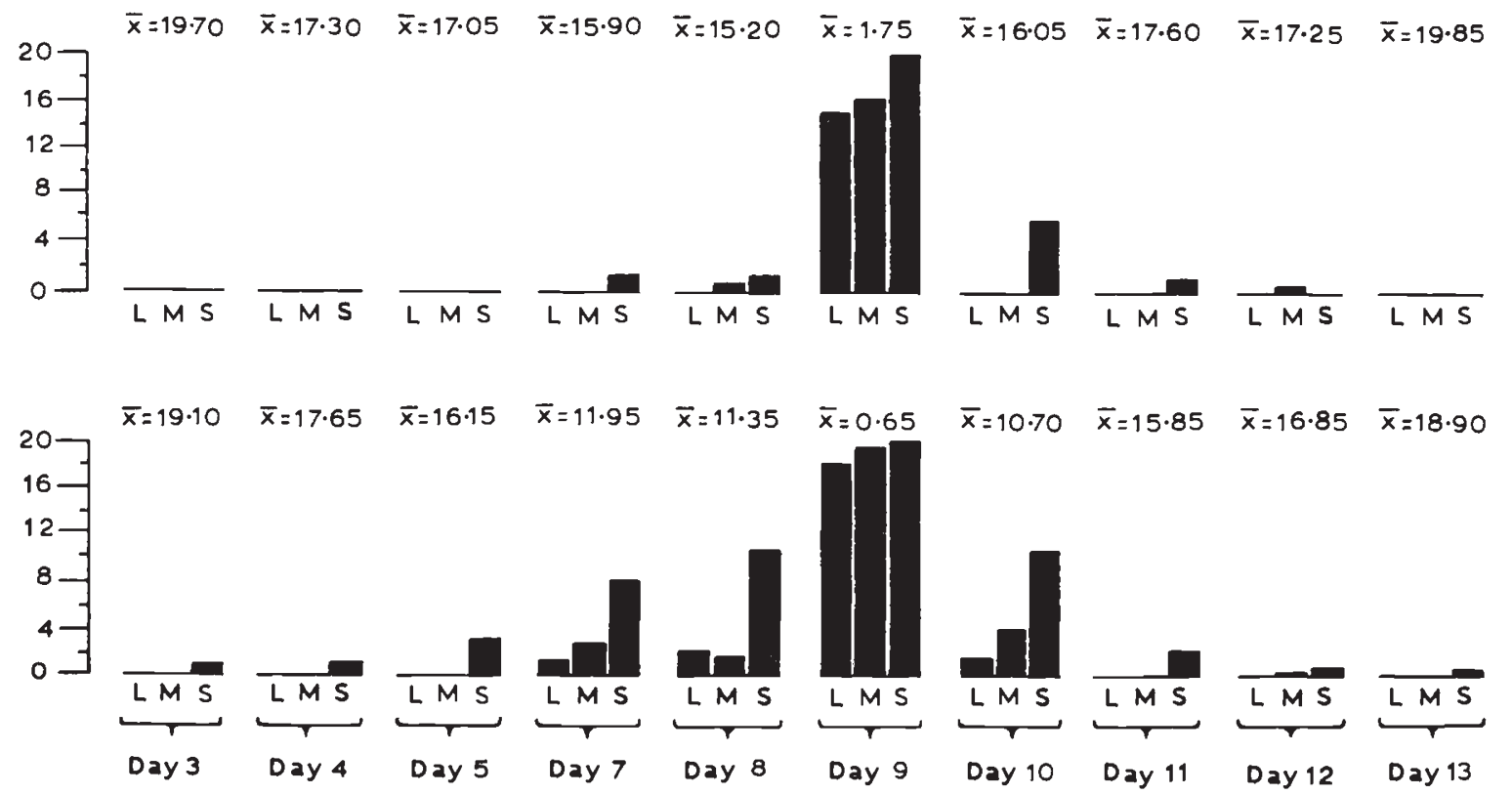

Figure 11 Histograms showing the numbers of univalents recorded in each of the three size groups ( $L$, M and $S$ ) for the two individuals sampled per day in the experiment involving 3 days at $40^{\circ} \mathrm{C}$ followed by a return to $30^{\circ} \mathrm{C}$. Note that essentially similar distributions are found within the three size groups as chiasma frequencies fall and rise.

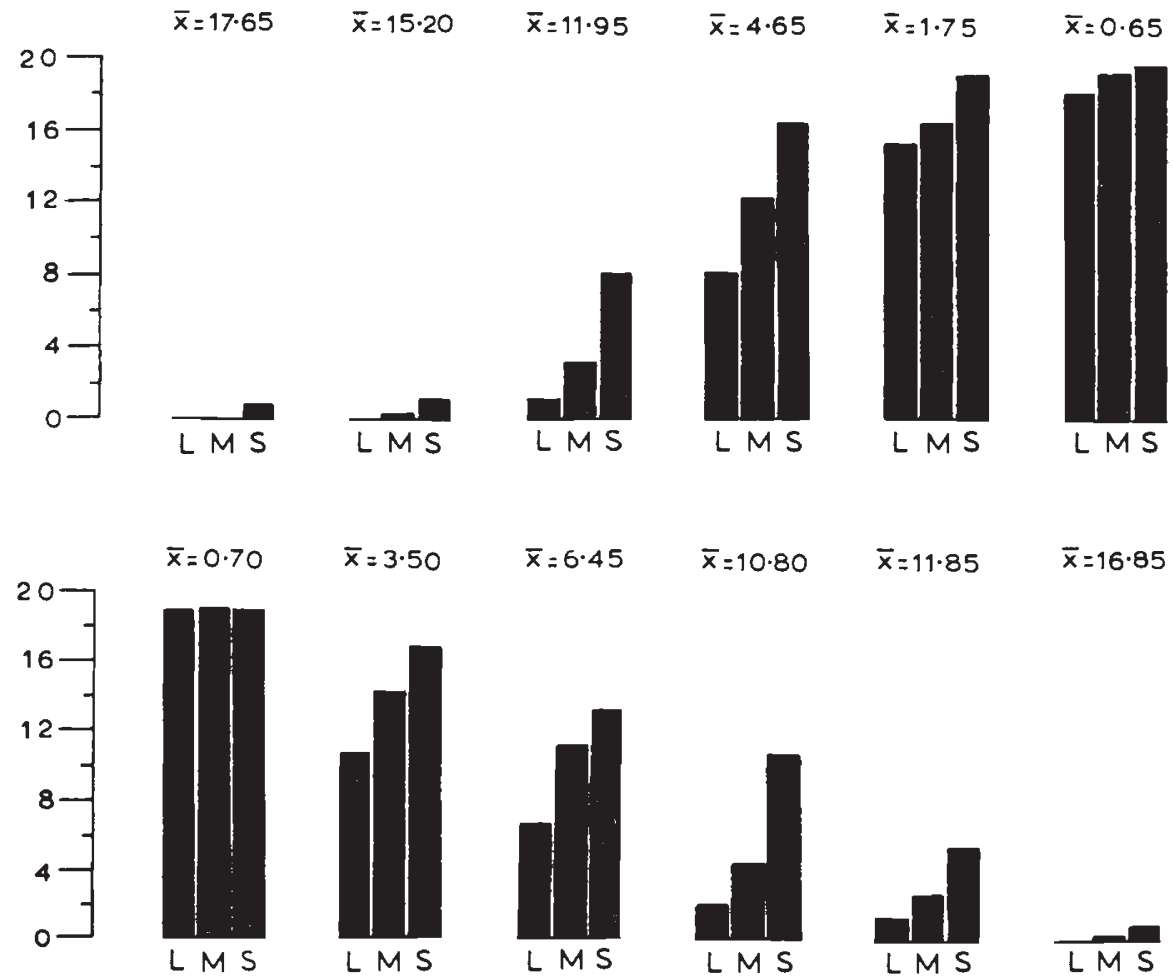

Figure 12 Selected histograms showing the number of univalents in each of the 3 size groups ( $L, M$ and $S)$ as chiasma frequencies fall (top line) or rise (bottom line). These individuals are taken from different experiments and are arranged to show comparable ranges of univalent frequencies. 
chiasma frequency has already been published in an earlier review (Henderson, 1970), together with an outline of the general interpretations which I place upon the four effects. These are as follows:

(4) an effect at G1 or on spermatogonial cells, prior to the onset of meiosis.

(3) an effect on chromosome pairing. This is the largest effect, the one first described in detail.

(2) an effect immediately prior to chiasma formation, at the end of zygotene, after chromosomes are paired.

(1) an effect which is possibly at the time of chiasma formation itself.

Effect 4 is a particularly interesting effect in that it suggests that something happens to chromosomal DNA molecules, prior to them replicating in the premeiotic $S$ phase, which can modify them, or their association with chromosomal proteins, so that, when the chromosomes eventually cross-over in pachytene, the numbers of chiasmata formed can be changed. It would seem probable that, when cells normally pass from gonial stages to, and through, premeiotic $\mathrm{S}$, molecular changes take place within the DNA molecules which facilitate subsequent exchange taking place at zygotene/ pachytene. If cells pass through this period at the elevated temperature of $40^{\circ} \mathrm{C}$ it would appear that these molecular changes are modified in such a way that more exchanges (and chiasmata) can be formed.

In this context it is interesting to note that cells exhibiting this effect often appear to show some inhibition of the growth which precedes meiosis. When spermatogonia become spermatocyte mother cells they normally grow considerably in size to give fully formed spermatocytes. Most of this growth takes place between their premeiotic $S$ phase and the first recognisable leptotene stage of meiosis. In spermatocytes showing an increase in chiasma frequency (Effect 4 ), following heattreatment of this stage, it can be seen that such growth has sometimes only partly been completed. Affected cells can vary in size from spermatogonia to normal spermatocytes. They have a great deal in common with what was seen and described before in some individuals, when, in the testes of individuals showing advanced univalence in their fully grown spermatocytes, small cells could sometimes be found, possessing diminutive chromosomes with rather higher chiasma frequencies. This was termed premature meiotic induction (Henderson, 1962). In the present studies, comparable individuals mosaic for spermatocyte development were occasionally found (only the most fully grown spermatocytes in such individuals being scored to provide the mean chiasma frequency). But, when the major increase in chiasma frequency is found (Effect 4), most of the cells tend to be a little smaller than usual, although their chromosomes are much more normal in length and appearance than those found in cells showing premature meiotic induction.

Effect 3, on early prophase nuclei, soon after the completion of premeiotic DNA synthesis must, for the reasons discussed above, be an effect on synapsis, at the time that pairing is taking place and being rendered effective, in order that chiasma formation can occur. This, I have suggested earlier (Henderson, 1962) is most likely to involve the acceleration of the functional doubling of the chromosomes into visibly discrete chromatids, with the concomitant failure of chromosomes to pair effectively. Effective pairing may be restricted to initial contact points-first to pair and last to duplicate visibly. This explanation is supported by various levels of reduced pairing (asynapsis and desynapsis) in univalent-containing individuals, by the visible doubleness of all unpaired segments in such cells and, in individuals showing total univalence, by the complete absence of typical pachytene stages, nuclei at a comparable stage of cellular development and chromosome contraction being filled with mostly unpaired, visibly double chromatids.

Effect 2 may also involve some aspect of chromosome pairing, but the exact nature of this effect is less clear. There may be a reduction in the effective nature of the synapsis which has taken place, prior to the time of chiasma formation, which then leads to a reduction in the subsequent chiasma forming potential of the chromosomes (i.e., the chromosomes may undergo something comparable to localised, though not visible, molecular desynapsis and hence not take full advantage of the fact that they were paired). The occasional production of univalents during Effect 2 in Schistocerca and also during Effect 2 in similar experiments carried out with Melanoplus differentialis (Henderson, in preparation) might be held to support this line of reasoning. If this is so, the time of chiasma formation during prophase should be later than the time during which Effect 2 is obtained.

Effect 1, involving late zygotene nuclei could involve an effect on the breakage or exchange taking place at the time of chiasma formation itself. It this does prove to be the case, it would enable one to pinpoint the time of crossing-over to within one day of the 13 day interval between metaphase $\mathrm{I}$ and premeiotic $\mathrm{S}$ at $30^{\circ} \mathrm{C}$ (Henderson, 1966). 
Taking into consideration the accelerating affects of the initial days at $40^{\circ} \mathrm{C}\left(Q_{10}=2 \cdot 3\right)$ the time during which chiasma formation may take place in Schistocerca would be approximately 5 days prior to diplotene and metaphase I (which are both completed within 1 day) at $30^{\circ} \mathrm{C}$ and some 8 days after the completion of premeiotic DNA synthesis. At $40^{\circ} \mathrm{C}$ this would be reduced to some $2 \frac{1}{2}$ days prior to metaphase $I$ and $3 \frac{1}{2}$ days after $S$. However, the data as they stand do not rule out the possibility that Effect 1 also involves indirect action and that the time of chiasma formation could be an insensitive stage immediately following the time of this effect, in even later prophase nuclei. This possibility is considered to be less likely in the light of experiments which have been carried out on other Orthopterans, including Locusta migratoria (Buss, 1971). In these species, Effect 1 increases are produced by heat-treatments as in Schistocerca, but even later in first meiotic prophase. There would appear to be very little time for chiasma formation to proceed to completion much later than the time of this effect in some cases, and the most simple interpretation of Effect 1 is that it corresponds to at least part of the time of crossing-over itself, though not necessarily the whole of it. Further discussion of the current experimental evidence bearing on the time and place of meiotic crossing over have been reviewed in detail at an earlier date (Henderson, 1970) and will be discussed again in a future publication, and need not be re-listed here.

The attempts which have been made by other workers to demonstrate effects of elevated temperature on chiasma formation or crossing-over have yielded variable results. Some workers have found increases, others decreases, some both increases and decreases, while others have found no effects at all. No one has previously demonstrated four repeatable effects correlated with different stages of the meiotic process, as demonstrated here in Schistocerca. From our experience with other species we may conclude that at least some of this variability is likely to be due to inher- ent differences in the biology of the organisms involved. It is also possible that the times and treatments used by different workers, with differing materials, led to the sampling of only one or two of the effects described above in Schistocerca, or to missing them due to the temperature or sampling programme involved.

Of particular interest is the early work of Dowrick (1957) on Tradescantia. With constant high temperatures he obtained an initial increase in chiasma frequency (corresponding to Effect 1 in Schistocerca), following by a dramatic decrease to total univalence (corresponding to Effect 3 ). This work is of value in revealing the occurrence of the initial increase in chiasma frequency (Effect 1 ) in plant material. Its production in such unrelated forms as a plant and three species of insect suggest that it has some fairly basic significance. The suggestion that it corresponds to an effect at the time of chiasma formation itself deserves serious consideration.

\section{REFERENCES}

BUSS, M. E. 1971. The Experimental Control of Chromosome Pairing and Chiasma Formation. Ph.D. Thesis, University of Cambridge.

DOWRICK, G. J. 1957. The influence of temperature on meiosis. Heredity, 11, 37-49.

HENDERSON, S. A. 1962. Temperature and chiasma formation in Schistocerca gregaria. II. Cytological effects at $40^{\circ} \mathrm{C}$ and the mechanism of heat-induced univalence. Chromosoma, $13,437-463$.

HENDERSON, S. A. $1963 a$. Temperature and chiasma formation in Schistocerca gregaria. I. An analysis of the response at a constant $40^{\circ} \mathrm{C}$. Heredity, $18,77-94$.

HENDERSON, S. A. 1963 b. Chiasma distribution at diplotene in a locust. Heredity, 18, 173-190.

HENDERSON, S. A. 1966. The time of chiasma formation in relation to the time of DNA synthesis. Nature, 211, 10431047.

HENDERSON, S. A. 1970. The time and place of meiotic crossingover. Ann. Rev. Genet., 4, 295-324.

JOHN, B. AND NAYLOR, B. 1961. Anomalous chromosome behaviour in the germ line of Schistocerca gregaria. Heredity, 16, 187-198. 